\title{
Evidence-Based Pharmacotherapy of Generalised Anxiety Disorder: Focus on Agomelatine
}

\author{
Dan J. Stein
}

Received: April 12, 2021 / Accepted: July 12, 2021 / Published online: August 21, 2021

(c) The Author(s) 2021

\section{ABSTRACT}

Recent network meta-analyses support the use of pharmacotherapy in patients with generalised anxiety disorder (GAD). Compared with placebo, drug treatment can improve symptoms and quality of life, and is more effective in preventing relapse. Selective serotonin reuptake inhibitors and serotonin-norepinephrine reuptake inhibitors are generally considered the first-line agents of choice in GAD, but in some patients, an alternative evidence-based

Supplementary Information The online version contains supplementary material available at https:// doi.org/10.1007/s12325-021-01860-1.

D. J. Stein ( ()

SAMRC Unit On Risk and Resilience in Mental

Disorders, Department of Psychiatry and

Neuroscience Institute, Groote Schuur Hospital,

University of Cape Town, Anzio Road, Cape Town

7925, South Africa

e-mail: dan.stein@uct.ac.za treatment with a different mechanism of action may also be considered (e.g. those with severe $\mathrm{GAD}$, inadequate response, adverse effects and/ or contraindications). One example is agomelatine, a melatonin receptor agonist and serotonin $2 \mathrm{C}\left(5-\mathrm{HT}_{2 \mathrm{C}}\right)$ receptor antagonist, which has been shown to have efficacy that is greater than placebo in patients with GAD, and to have a tolerability profile that compares favourably with that of escitalopram. Both agomelatine and escitalopram are efficacious in treating patients with GAD, including those with severe symptoms.

Keywords: Agomelatine; Anxiety disorders; Serotonin 5-HT2C receptor; Serotonin uptake inhibitors 


\section{Key Summary Points}

Why carry out this review?

Generalised anxiety disorder (GAD) is a prevalent psychiatric disorder typically treated with selective serotonin reuptake inhibitors and serotonin-norepinephrine reuptake inhibitors.

Patients in whom these agents are ineffective or poorly tolerated require alternative treatments; this review summarises novel agents with alternate mechanisms of action, and includes more detailed discussion of the melatonin receptor agonist and serotonin 2C receptor antagonist agomelatine.

\section{What was learned from the review?}

Of several therapeutic drugs with a mechanism of action beyond targeting serotonergic pathways, only the anticonvulsant pregabalin has been granted regulatory approval (in Europe) for the treatment of GAD.

Although not approved in this indication, agomelatine is another such agent with therapeutic evidence supporting its efficacy and safety in the treatment of GAD.

\section{DIGITAL FEATURES}

This article is published with digital features, including a video abstract, to facilitate understanding of the article. To view digital features for this article go to https://doi.org/10.6084/ m9.figshare.14959524.

\section{INTRODUCTION}

Pharmacotherapy has long been a mainstay of treatment in generalised anxiety disorder (GAD). Since the 1970s, each successive decade has brought new treatment options: either completely new chemical entities with novel mechanisms of action or established psychopharmacological agents with new evidence of efficacy against anxiety symptoms. This narrative review summarises these developments and emphasizes key advances as well as future areas for investigation, with a particular focus on agomelatine.

The main classes of drugs used to treat GAD are shown in Table 1. Benzodiazepines (BZDs), while effective and fast-acting in the treatment of GAD, have now largely been supplanted by the selective serotonin reuptake inhibitors (SSRIs; e.g. escitalopram) and serotonin-norepinephrine reuptake inhibitors (SNRIs; e.g. venlafaxine) because of the well-documented risks of dependence and other adverse outcomes associated with BZDs. A range of current clinical guidelines list SSRIs and SNRIs as first-line choices in GAD [1-6]; they are effective and well tolerated in many but not all patients.

Tricyclic antidepressants have similar efficacy to BZDs in the treatment of GAD; however, their slower onset of anxiolytic action and range of clinical adverse effects, such as those associated with muscarinic receptor antagonism, limit their wider use. Buspirone is an azapirone with efficacy over the short term (4-9 weeks), but that may be less effective than BZDs [7], hydroxyzine is an antihistamine with the potential for sedation [8], trifluoperazine is a first-generation antipsychotic agent that was approved in the USA for short-term treatment of GAD [9] and used in patients not responsive to safer agents, but subsequently withdrawn from the US market for reasons unrelated to efficacy or safety [10], and pregabalin is a gamma-aminobutyric acid (GABA)-ergic agent [11], which received European Medicines Agency but not US Food and Drug Administration approval (Table 1). Second-generation ('atypical') antipsychotics (SGAs) are used offlabel for anxiety (quetiapine showing significant benefit in GAD $[12,13])$, but have failed to gain regulatory approval for the treatment of GAD because of safety concerns.

Therefore, additional medications with novel mechanisms of action and better tolerability may provide useful therapeutic 
Table 1 Pharmacotherapies used in the off-label treatment of generalised anxiety disorder (GAD), except where otherwise stated

\begin{tabular}{|c|c|c|c|c|}
\hline$\overline{\text { Class }}$ & Abbreviation & $\begin{array}{l}\text { Important } \\
\text { example(s) }\end{array}$ & $\begin{array}{l}\text { Approved for } \\
\text { use in GAD } \\
(\operatorname{market}(s))[38]\end{array}$ & Efficacy/tolerability \\
\hline Anticonvulsants & - & $\begin{array}{l}\text { Pregabalin } \\
\text { Tiagabine }\end{array}$ & $\begin{array}{l}\text { Yes }(E U, \text { ROW })^{\mathrm{a}} \\
\text { No }\end{array}$ & $\begin{array}{l}\text { Pregabalin considered a second-line } \\
\text { option [1] }\end{array}$ \\
\hline Azapirones & - & Buspirone & No & $\begin{array}{l}\text { May be less effective than BZD despite } \\
\text { good tolerability profile }\end{array}$ \\
\hline Benzodiazepines & $\mathrm{BZD}$ & $\begin{array}{l}\text { Alprazolam } \\
\text { Lorazepam }\end{array}$ & $\begin{array}{l}\text { Yes (USA) } \\
\text { No }\end{array}$ & Efficacious; significant adverse events \\
\hline Melatonin receptor agonists & MRA & Agomelatine & No & $\begin{array}{l}\text { Efficacy data available; good } \\
\text { tolerability profile }\end{array}$ \\
\hline $\begin{array}{l}\text { Noradrenergic and specific } \\
\text { serotonergic } \\
\text { antidepressants }\end{array}$ & NaSSA & Mirtazapine & No & Limited data available \\
\hline $\begin{array}{l}\text { Norepinephrine-dopamine } \\
\text { reuptake inhibitors }\end{array}$ & NDRI & Bupropion & No & Limited data available \\
\hline $\begin{array}{l}\text { First-generation } \\
\text { antipsychotics }\end{array}$ & FGA & Trifluoperazine & No & Withdrawn from US market \\
\hline $\begin{array}{l}\text { Second-generation } \\
\text { antipsychotics }\end{array}$ & SGA & Quetiapine & No & $\begin{array}{l}\text { Not approved for use in GAD because } \\
\text { of adverse events }\end{array}$ \\
\hline \multirow[t]{2}{*}{$\begin{array}{l}\text { Serotonin-norepinephrine } \\
\text { reuptake inhibitors }\end{array}$} & \multirow[t]{2}{*}{ SNRI } & $\begin{array}{l}\text { Desvenlafaxine } \\
\text { Duloxetine }\end{array}$ & $\begin{array}{l}\text { No } \\
\text { Yes (USA, } \\
\text { ROW) }\end{array}$ & \multirow[t]{2}{*}{$\begin{array}{l}\text { SSRIs and SNRIs considered first-line } \\
\text { agents for GAD; each agent has } \\
\text { specific adverse event profile }\end{array}$} \\
\hline & & Venlafaxine & $\begin{array}{l}\text { Yes (China, } \\
\text { Europe, UK, } \\
\text { USA, ROW) }\end{array}$ & \\
\hline \multirow{4}{*}{$\begin{array}{l}\text { Selective serotonin reuptake } \\
\text { inhibitors }\end{array}$} & \multirow[t]{4}{*}{ SSRI } & Escitalopram & Yes (USA, EU) & \\
\hline & & Fluoxetine & No & \\
\hline & & Sertraline & No & \\
\hline & & Vortioxetine & No & \\
\hline
\end{tabular}


Table 1 continued

\begin{tabular}{lllll}
\hline Class & Abbreviation & $\begin{array}{l}\text { Important } \\
\text { example(s) }\end{array}$ & $\begin{array}{l}\text { Approved for } \\
\text { use in GAD } \\
(\text { market(s) })[38]\end{array}$ & Efficacy/tolerability \\
\hline Tricyclic antidepressants & TCA & $\begin{array}{l}\text { Amitriptyline } \\
\text { Imipramine }\end{array}$ & No & $\begin{array}{c}\text { Efficacious, but disadvantageous } \\
\text { adverse event profiles }\end{array}$ \\
& & Nortriptyline & No & \\
\hline
\end{tabular}

EU European Union, GAD generalised anxiety disorder, ROW rest of world, UK United Kingdom, USA United States

a Argentina, Brazil, Hong Kong, India, Indonesia, Malaysia, Mexico, Russia, Singapore, Switzerland, Thailand, Turkey, Ukraine

b Argentina, Australia, Canada, Czech Republic, Denmark, Hong Kong, Iceland, Ireland, Israel, Liechtenstein, Malaysia, Mexico, Netherlands, New Zealand, Norway, Portugal, Russia, Singapore, Spain, Switzerland, Thailand

${ }^{c}$ Canada, Ireland, various South American countries

alternatives for the treatment of GAD. A range of newer agents have received attention, including serotonergic agents (e.g. ondansetron, vortioxetine), noradrenergic and specific serotonergic antidepressants (e.g. mirtazapine), norepinephrine-dopamine reuptake inhibitors (e.g. bupropion), beta-blockers (e.g. propranolol), glutamatergic agents (e.g. ketamine), neuropeptides and neurosteroids (e.g. mifepristone), and cannabinoids and herbal agents [14]. However, as noted below, many trials have been negative or had small samples sizes, so that there is limited support for such agents. The melatonin receptor agonist and serotonin $2 \mathrm{C}$ $\left(5-\mathrm{HT}_{2 \mathrm{C}}\right)$ receptor antagonist agomelatine provides another novel mechanism of action, and has consistently been found to be efficacious and well tolerated in GAD, and is discussed in more detail here.

This article is based on previously conducted studies and does not contain any new studies with human participants or animals performed by the author.

\section{EVIDENCE TO SUPPORT PHARMACOTHERAPY IN GAD}

Recent network meta-analyses (NMAs) provide useful overviews of the available evidence to support different classes of anxiolytic drug, and individual drugs within those classes [15-17]. In an analysis of 57 clinical trials, Chen et al. found that all classes of pharmacotherapy for GAD were more efficacious (based on changes in Hamilton Anxiety Rating Scale [HAM-A]) than placebo, with the exception of serotoninmodulating drugs and SGAs [15]. The most efficacious drug classes, relative to placebo, were the norepinephrine-dopamine reuptake inhibitors, followed by the noradrenergic and specific serotonergic antidepressant. Importantly, however, the volume of data on these classes was considerably smaller than for SSRIs, SNRIs, BZDs and other classes. BZDs, as a class, showed the smallest efficacy difference versus placebo among the effective drug classes. Most pharmacological interventions had greater treatment effects than psychological interventions [15].

Separately, Slee and colleagues performed an NMA of 89 trials of individual anxiolytic agents that included more than 25,000 patients with GAD [16]. The most efficacious drugs (again, based on change in HAM-A score) were duloxetine, pregabalin, venlafaxine and escitalopram; interestingly, the SGA quetiapine was found to be more efficacious than duloxetine, but was limited by its poor tolerability. There was favourable evidence in terms of efficacy and tolerability for several other drugs, but the authors highlighted that sample sizes for these agents were small (buspirone, fluoxetine, sertraline, mirtazapine and agomelatine) [16]. Notably, this NMA did not include trials 
reported before 1994, and may therefore have excluded a significant volume of relevant data.

Lastly, He et al. conducted an NMA of individual first-line pharmacotherapies (SSRIs and SNRIs) for the treatment of GAD [17], and included 41 trials of at least 4 weeks' duration that used the HAM-A as the main measure of efficacy $(n>15,000)$. With the exception of fluoxetine and vortioxetine, all of the drugs included in the analysis had greater anxiolytic efficacy than placebo. Consistent with the findings of Slee and colleagues [16], drugs with the greatest effect on HAM-A scores, relative to placebo, were duloxetine, escitalopram and venlafaxine [17]; pregabalin was not included in the analysis.

Other meta-analyses of pharmacotherapy for GAD have been useful in indicating that a number of classes of medication are useful for GAD [18], that anxiolytic effects persist beyond the active treatment period [19], that maintenance treatment is effective in preventing relapse [20], and that effective treatment improves quality of life [21]. Much research is needed in this area, including trials of more representative patients [22], including those with significant comorbidity [23], trials of GAD across the patients' lifespan [24, 25], pragmatic trials [26], and trials of drugs that target novel mechanisms of action [14]. Future research may also include work based on translational neuroscience [27], epidemiological studies [28] and big data [29], and should also address the question of whether clinical characterization may improve personalized treatment [30].

\section{NEWER DRUGS: AGOMELATINE}

The network meta-analyses discussed here emphasize that there is a robust evidence base supporting the use of established drug classes, particularly SNRIs and SSRIs, in the treatment of GAD. However, there have been few studies focused on severe GAD in particular, and there is a need for newer agents with novel mechanisms of action to ensure that there are different treatment options available for people with GAD, including those who do not respond to or cannot tolerate established therapies [31].
Among these newer agents is agomelatine, which Stein and colleagues systematically compared with placebo and active comparators in patients with GAD [31-35]. Importantly, in the NMA by Slee and colleagues mentioned earlier, agomelatine was the only newer agent to show efficacy compared with placebo in the treatment of GAD [16].

In a preliminary 12 -week study in 121 patients with GAD [35], HAM-A score curves for agomelatine (25-50 $\mathrm{mg}$ /day) and placebo began to separate after 4 weeks. At week 12 , the estimated difference between the treatment groups (in mean change in HAM-A score vs baseline) was -3.28 (95\% confidence interval $[-6.41,-$ $0.15] ; \quad P=0.04)$. Subsequently, agomelatine (25-50 mg/day) was found to have comparable efficacy to escitalopram (10-20 mg/day), in terms of both reductions in HAM-A scores and response rates, in a randomised placebo-controlled trial $(n=412)$. In this trial, escitalopram was used as the comparator in order to validate the study results. Although both active treatments were superior to placebo in the overall study group and in patients with severe GAD (defined as a baseline HAM-A score $\geq 25$ ), fewer agomelatine than escitalopram recipients experienced severe adverse events (AEs; $n=1$ vs 4 , respectively) or AEs that led to treatment discontinuation ( $n=3$ vs 10 , respectively).

Since the publication of these two studies, subsequent trials have confirmed the efficacy and safety of agomelatine in the treatment of GAD at lower daily dosages (10-25 mg/day) [33], and in a head-to-head trial versus escitalopram in severe GAD [32]. In the latter study, both treatments were associated with clinically significant decreases in HAM-A scores at week 12 , and were thus efficacious in treating patients with severe GAD. There were no significant differences between agomelatine and escitalopram in terms of the size of the reductions in HAM-A score from baseline, in either the overall study group (mean \pm standard deviation, $-16.0 \pm 9.1 \quad$ vs $\quad-16.9 \pm 8.4$, respectively) or in more severely anxious patients $(-16.4 \pm 9.5$ vs $-17.4 \pm 8.6$, respectively; Fig. 1) [32]. However, the pre-established criteria for non-inferiority of agomelatine versus escitalopram were not met (HAM-A total score 


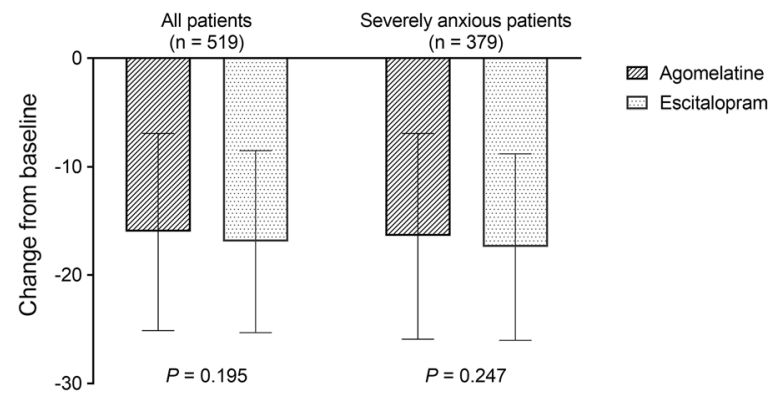

Fig. 1 Mean change between baseline and 12 weeks in Hamilton Anxiety Rating Scale (HAM-A) in a randomised trial comparing agomelatine $(25-50 \mathrm{mg} /$ day) versus escitalopram $(10-20 \mathrm{mg} /$ day) in the treatment of generalised anxiety disorder [32]. Error bars represent standard deviation. 'Severe anxiety' was defined as patients with a HAM-A total score $\geq 25$ and a CGI-S (Clinical Global Impression-Severity scale) rating $\geq 5$ at baseline

estimate, - 0.91; standard error, 0.69; 95\% confidence interval $-2.26,0.44 ; P=0.195)$. Agomelatine was associated with a numerically lower incidence of AEs compared with escitalopram (46.9\% vs $58.8 \%$ ) [32].

Maintenance agomelatine treatment has been shown to be more effective than placebo in preventing relapse in patients with GAD [34]. Over a 6-month period, $19.5 \%$ of patients receiving agomelatine $(25-50 \mathrm{mg} /$ day) experienced relapse, compared with $30.5 \%$ of placebo recipients [hazard ratio (HR) $0.582 ; P=0.046$ ]. Agomelatine was also associated with a significantly lower relapse rate versus placebo in patients with severe GAD (20.8\% vs $42.9 \%$; HR 0.407; $P=0.006$ ).

Agomelatine has also been found to be efficacious in anxious depression, as discussed in a separate article in this supplement. Symptoms of anxiety are present in $40-50 \%$ of patients with major depressive disorder (MDD), and are associated with greater functional impairment and a higher risk of suicide in this patient group [36]. In a pooled analysis of six trials in patients with MDD, agomelatine was found to have a significantly greater effect on HAM-A scores over 6-8 weeks compared with placebo (between-group difference at endpoint, 3.13 points; $P<0.005$ ), and a comparable or greater effect versus fluoxetine (1.24 points; $P=0.137)$, sertraline (2.36 points; $P=0.016$ ) or venlafaxine (0.82 points; $P=0.327$ ) [36]. Findings were similar for the subgroup of patients with more severe anxiety symptoms.

\section{GAD TREATMENT GUIDELINES}

In current guidelines for the management of GAD, SSRIs and SNRIs are typically recommended as first-line agents of choice [1-6]. Agomelatine has also demonstrated efficacy in anxiety symptoms in MDD [36], as well as in GAD [32, 34, 37]. Considering its evidence base in GAD to be comparable to that for escitalopram, the Anxiety Disorders Association of Canada recommends agomelatine as a first-line agent [4]. Agomelatine is considered as a second-line agent (in patients with GAD resistant to SSRI or SNRI treatment) by the Royal Australian and New Zealand College of Psychiatrists [1] and the South African Society of Psychiatrists [6]. Thus, agomelatine has an established place in therapy as an alternative to initial treatment with an SSRI or SNRI, and as an option in patients who do not respond, or have only a partial response, to first-line GAD. Its use in GAD would be off-label since it is not approved for use in this indication.

\section{CONCLUSIONS}

The evidence base on pharmacotherapy for GAD has expanded greatly in the last few decades, and supports the use of SSRIs and SNRIs as first-line agents. As not all patients respond to or are able to tolerate these agents, more recently there has also been work on a range of medications with different mechanisms of action (e.g. melatonin receptor agonists, NMDA receptor antagonists, neuropeptides, and neurosteroids). Unfortunately, a number of such trials have failed (e.g., neuropeptides such as L-759274, SSR149415, and BMS-562086 [38]). Indeed, at the current time, for the majority of these medications, evidence of their use in GAD is limited and further research is required. Agomelatine has been shown to be efficacious and well tolerated in patients with GAD, 
including those with more severe symptoms, providing physicians and patients alike with another useful option.

\section{ACKNOWLEDGEMENTS}

Funding. This supplement has been sponsored by Servier, France. This funding includes payment of the Journal's Rapid Service Fee and Open Access Fee.

Medical Writing Assistance. We would like to thank Richard Crampton of Springer Healthcare Communications, who wrote the first draft of this article. Funding for this medical writing assistance was provided by Servier.

Authorship. The named author meets the International Committee of Medical Journal Editors (ICMJE) criteria for authorship for this article, takes responsibility for the integrity of the work as a whole, and has given their approval for this version to be published.

Author Contributions. Dr Stein prepared the lecture on which this article is based, read, revised and edited all drafts, and approved the final draft for submission.

Prior Presentation. This editorial and the accompanying articles in this supplement are based on presentations made by the authors at a Servier-funded virtual symposium titled "Industry Science Exchange" that took place at the European College of Neuropsycopharmacology 33rd Congress in September 2020.

Disclosures. Dan J. Stein has received research grants and/or consultancy honoraria from Abbott, ABMRF/The Foundation for Alcohol Research, AstraZeneca, Biocodex, Eli-Lilly, GlaxoSmithKline, Jazz Pharmaceuticals, Johnson \& Johnson, Lundbeck, National Responsible Gambling Foundation, Novartis, Orion, Pfizer, Pharmacia, Roche, Servier, Solvay, Sumitomo, Sun, Takeda, Tikvah and Wyeth, and has received research grants and/or consultancy honoraria in the last 3 years from Johnson \&
Johnson, Lundbeck, Servier and Takeda. This includes an honorarium from Servier for the presentation on which this publication is based.

Compliance with Ethics Guidelines. This article is based on previously conducted studies and does not contain any new studies with human participants or animals performed by the author.

Data Availability. Data sharing is not applicable to this article as no datasets were generated or analysed during the current study.

Open Access. This article is licensed under a Creative Commons Attribution-NonCommercial 4.0 International License, which permits any non-commercial use, sharing, adaptation, distribution and reproduction in any medium or format, as long as you give appropriate credit to the original author(s) and the source, provide a link to the Creative Commons licence, and indicate if changes were made. The images or other third party material in this article are included in the article's Creative Commons licence, unless indicated otherwise in a credit line to the material. If material is not included in the article's Creative Commons licence and your intended use is not permitted by statutory regulation or exceeds the permitted use, you will need to obtain permission directly from the copyright holder. To view a copy of this licence, visit http://creativecommons.org/licenses/bync/4.0/.

$\mathrm{i}$

\section{REFERENCES}

1. Andrews G, Bell C, Boyce P, et al. Royal Australian and New Zealand College of Psychiatrists clinical practice guidelines for the treatment of panic disorder, social anxiety disorder and generalised anxiety disorder. Aust N Z J Psychiatry. 2018;52(12): 1109-72.

2. Baldwin DS, Anderson IM, Nutt DJ, et al. Evidencebased pharmacological treatment of anxiety disorders, post-traumatic stress disorder and obsessivecompulsive disorder: a revision of the 2005 guidelines from the British Association for Psychopharmacology. J Psychopharmacol. 2014;28(5):403-39. https://doi.org/10.1177/0269881114525674. 
3. Bandelow B, Sher L, Bunevicius R, et al. Guidelines for the pharmacological treatment of anxiety disorders, obsessive-compulsive disorder and posttraumatic stress disorder in primary care. Int J Psychiatry Clin Pract. 2012;16(2):77-84. https:// doi.org/10.3109/13651501.2012.667114.

4. Katzman MA, Bleau P, Blier $\mathrm{P}$, et al. Canadian clinical practice guidelines for the management of anxiety, posttraumatic stress and obsessive-compulsive disorders. BMC Psychiatry. 2014;14(Suppl 1):S1. https://doi.org/10.1186/1471-244x-14-s1-s1.

5. National Institute for Health and Care Excellence. Generalised anxiety disorder and panic disorder in adults: management 2011 (updated 2019). 2019. https://www.nice.org.uk/guidance/cg113. Accessed 17 Dec 2020.

6. Stein DJ. Generalised anxiety disorder. S Afr J Psychiatry. 2013;19(3):175-9. https://doi.org/10.4102/ sajpsychiatry.v19i3.950.

7. Chessick CA, Allen MH, Thase M, et al. Azapirones for generalized anxiety disorder. Cochrane Database Syst Rev. 2006. https://doi.org/10.1002/ 14651858.CD006115.

8. Guaiana G, Barbui C, Cipriani A. Hydroxyzine for generalised anxiety disorder. Cochrane Database Syst Rev. 2010. https://doi.org/10.1002/14651858. CD006815.pub2.

9. Mendels J, Krajewski TF, Huffer V, et al. Effective short-term treatment of generalized anxiety disorder with trifluoperazine. J Clin Psychiatry. 1986;47(4):170-4.

10. US Food and Drug Administration. Stelazine (trifluoperazine hydrochloride). 2021. https://www. accessdata.fda.gov/scripts/cder/daf/index. $\mathrm{cfm}$ ?event $=$ overview.process\&ApplNo $=011552$. Accessed 07 May 2021.

11. Generoso MB, Trevizol AP, Kasper S, Cho HJ, Cordeiro Q, Shiozawa P. Pregabalin for generalized anxiety disorder: an updated systematic review and meta-analysis. Int Clin Psychopharmacol. 2017;32(1):49-55. https://doi.org/10.1097/YIC. 0000000000000147 .

12. Maher AR, Maglione M, Bagley S, et al. Efficacy and comparative effectiveness of atypical antipsychotic medications for off-label uses in adults: a systematic review and meta-analysis. JAMA. 2011;306(12): 1359-69. https://doi.org/10.1001/jama.2011.1360.

13. Maneeton N, Maneeton B, Woottiluk $\mathrm{P}$, et al. Quetiapine monotherapy in acute treatment of generalized anxiety disorder: a systematic review and meta-analysis of randomized controlled trials.
Drug Des Dev Ther. 2016;10:259-76. https://doi. org/10.2147/DDDT.S89485.

14. Garakani A, Murrough JW, Freire RC, et al. Pharmacotherapy of anxiety disorders: current and emerging treatment options. Front Psychiatry. 2020;11:595584. https://doi.org/10.3389/fpsyt. 2020.595584 .

15. Chen TR, Huang HC, Hsu JH, Ouyang WC, Lin KC. Pharmacological and psychological interventions for generalized anxiety disorder in adults: a network meta-analysis. J Psychiatr Res. 2019;118:73-83. https://doi.org/10.1016/j.jpsychires.2019.08.014.

16. Slee A, Nazareth I, Bondaronek P, Liu Y, Cheng Z, Freemantle N. Pharmacological treatments for generalised anxiety disorder: a systematic review and network meta-analysis. Lancet. 2019;393(10173):768-77. https://doi.org/10.1016/ s0140-6736(18)31793-8.

17. He H, Xiang Y, Gao F, et al. Comparative efficacy and acceptability of first-line drugs for the acute treatment of generalized anxiety disorder in adults: a network meta-analysis. J Psychiatr Res. 2019;118: 21-30. https://doi.org/10.1016/j.jpsychires.2019. 08.009 .

18. Bandelow B, Reitt M, Rover C, Michaelis S, Gorlich Y, Wedekind D. Efficacy of treatments for anxiety disorders: a meta-analysis. Int Clin Psychopharmacol. 2015;30(4):183-92. https://doi.org/10.1097/ YIC.0000000000000078.

19. Bandelow B, Sagebiel A, Belz M, Görlich Y, Michaelis S, Wedekind D. Enduring effects of psychological treatments for anxiety disorders: metaanalysis of follow-up studies. $\mathrm{Br} \mathrm{J}$ Psychiatry. 2018;212(6):333-8. https://doi.org/10.1192/bjp. 2018.49 .

20. Donovan MR, Glue P, Kolluri S, Emir B. Comparative efficacy of antidepressants in preventing relapse in anxiety disorders-a meta-analysis. J Affect Disord. 2010;123(1-3):9-16. https://doi.org/10. 1016/j.jad.2009.06.021.

21. Hofmann SG, Wu JQ, Boettcher H, Sturm J. Effect of pharmacotherapy for anxiety disorders on quality of life: a meta-analysis. Qual Life Res. 2014;23(4): 1141-53. https://doi.org/10.1007/s11136-0130573-8.

22. Hoertel N, Le Strat Y, Blanco C, Lavaud P, Dubertret C. Generalizability of clinical trial results for generalized anxiety disorder to community samples. Depress Anxiety. 2012;29(7):614-20. https://doi. org/10.1002/da.21937.

23. Schaffer A, McIntosh D, Goldstein BI, et al. The CANMAT task force recommendations for the 
management of patients with mood disorders and comorbid anxiety disorders. Ann Clin Psychiatry. 2012;24(1):6-22.

24. Gale CK, Millichamp J. Generalised anxiety disorder in children and adolescents. BMJ Clin Evid. 2016;2016:1002.

25. Goncalves DC, Byrne GJ. Interventions for generalized anxiety disorder in older adults: systematic review and meta-analysis. J Anxiety Disord. 2012;26(1):1-11. https://doi.org/10.1016/j.janxdis. 2011.08.010.

26. Roberge P, Provencher MD, Gaboury I, et al. Group transdiagnostic cognitive-behavior therapy for anxiety disorders: a pragmatic randomized clinical trial. Psychol Med. 2020. https://doi.org/10.1017/ S0033291720004316.

27. Williams LM, Goldstein-Piekarski AN, Chowdhry N, et al. Developing a clinical translational neuroscience taxonomy for anxiety and mood disorder: protocol for the baseline-follow up Research domain criteria Anxiety and Depression ("RAD") project. BMC Psychiatry. 2016;16:68. https://doi. org/10.1186/s12888-016-0771-3.

28. Stein DJ, Harris MG, Vigo DV, et al. Perceived helpfulness of treatment for posttraumatic stress disorder: findings from the World Mental Health Surveys. Depress Anxiety. 2020;37(10):972-94. https://doi.org/10.1002/da.23076.

29. Tai AMY, Albuquerque A, Carmona NE, et al. Machine learning and big data: implications for disease modeling and therapeutic discovery in psychiatry. Artif Intell Med. 2019;99:101704. https://doi.org/10.1016/j.artmed.2019.101704.

30. Maj M, Stein DJ, Parker G, et al. The clinical characterization of the adult patient with depression aimed at personalization of management. World Psychiatry. 2020;19(3):269-93. https://doi.org/10. 1002/wps.20771.

31. Stein DJ, Ahokas A, Márquez MS, et al. Agomelatine in generalized anxiety disorder: an active comparator and placebo-controlled study. J Clin
Psychiatry. 2014;75(4):362-8. https://doi.org/10. 4088/JCP.13m08433.

32. Stein DJ, Khoo JP, Ahokas A, et al. 12-week doubleblind randomized multicenter study of efficacy and safety of agomelatine (25-50 mg/day) versus escitalopram (10-20 mg/day) in out-patients with severe generalized anxiety disorder. Eur Neuropsychopharmacol. 2018;28(8):970-9. https:// doi.org/10.1016/j.euroneuro.2018.05.006.

33. Stein DJ, Ahokas A, Jarema M, et al. Efficacy and safety of agomelatine (10 or $25 \mathrm{mg} /$ day) in nondepressed out-patients with generalized anxiety disorder: a 12-week, double-blind, placebo-controlled study. Eur Neuropsychopharmacol. 2017;27(5):526-37. https://doi.org/10.1016/j. euroneuro.2017.02.007.

34. Stein DJ, Ahokas A, Albarran C, Olivier V, Allgulander C. Agomelatine prevents relapse in generalized anxiety disorder: a 6-month randomized, double-blind, placebo-controlled discontinuation study. J Clin Psychiatry. 2012;73(7):1002-8. https:// doi.org/10.4088/JCP.11m07493.

35. Stein DJ, Ahokas AA, de Bodinat C. Efficacy of agomelatine in generalized anxiety disorder: a randomized, double-blind, placebo-controlled study. J Clin Psychopharmacol. 2008;28(5):561-6. https:// doi.org/10.1097/JCP.0b013e318184ff5b.

36. Stein DJ, Picarel-Blanchot F, Kennedy SH. Efficacy of the novel antidepressant agomelatine for anxiety symptoms in major depression. Hum Psychopharmacol. 2013;28(2):151-9. https://doi.org/10.1002/ hup. 2294.

37. Stein DJ, Khoo JP, Picarel-Blanchot F, Olivier V, Van Ameringen M. Efficacy of agomelatine 25-50 mg for the treatment of anxious symptoms and functional impairment in generalized anxiety disorder: a metaanalysis of three placebo-controlled studies. Adv Ther. 2021;38(3):1567-83. https://doi.org/10.1007/ s12325-020-01583-9.

38. Adis Insight. (Online Database), Adis International Ltd., Springer. https://adisinsight.springer.com/. Accessed 5 May 2021. 